\title{
A bibliometric approach to evaluating the impact of national libraries
}

\author{
David Hunter, Paul Hambelton
}

\begin{abstract}
In order to understand the value to society of a national library, it is essential to go beyond counting usage figures and understand impacts; 'the difference that the library makes'. The paper suggests that, for the National Library of Scotland (NLS), a key impact is the generation of new knowledge. A viable proxy for measuring this impact is establishing the number of publications produced in which the authors cite the use of NLS collections or services. The paper proposes a simple methodology for estimating the number of such research outputs through a bibliometric analysis of Google Scholar and other research resources.
\end{abstract}

\section{Introduction - demonstrating the value of national libraries}

Increasingly, as funders prioritise spending decisions, libraries are expected to demonstrate not only that they are efficient and productive, but also the impact they make. This shift towards a focus on impacts and outcomes (as opposed to outputs, still less inputs) is challenging for all libraries, but national libraries face particular and unusual difficulties in demonstrating their impacts.

This stems from the diffuse nature of the user base or 'audience' of a national library. National libraries are at the same time both research libraries and public libraries. But the 'research community' that they serve is much more difficult to pin down than for most academic research libraries, where staff and students of a university are normally the main clients. Similarly, the 'public community' served by national libraries is not clearly defined by the local geography, unlike most public libraries.

\section{Authors}

David Hunter is responsible for strategic planning, policy and performance management at the National Library of Scotland, where he has worked for eight years. His background is in the voluntary and public sectors, especially in the field of transport planning and disability. He is a member of the ESRC's Grant Advisory Panel and professional interests include evaluation and consumer interests.

Paul Hambelton is Strategy and Performance Assistant, National Library of Scotland.

Email: d.hunter@nls.uk 
National libraries have no specified clientele or primary user group like public or university libraries. Therefore, output data cannot be set in comparison to "members of the population". This means that national libraries cannot easily sample, interview or query their user community; as a result, establishing who uses them, why and how are especially difficult questions for national libraries to answer.

(International Organization for Standardization, 2009, 5.)

It has previously been argued that

Thinking about the outcomes that we want to see as a result of our mission as a national library ... requires us to think about what our users do with the resources they access at NLS (users being, readers, exhibition visitors, remote digital users etc). Do they use these resources to create new valuable knowledge? Or is their interaction with NLS resources and services superficial?

(Hunter, 2009, 6)

These questions are crucial, as they are central to the key question 'What difference does NLS make?'; or to put it more bluntly, 'How would the world be a worse place without NLS?' and ultimately 'Why should we fund you?'

In order answer these questions, we must do two things. Firstly, we need to succinctly describe a national library's contribution to society; and secondly we need to find a way to quantify that contribution. In the paper referred to above, it was suggested that

One solution may lie in exploring the scope to capture and use bibliometric data. Many newly-published books and journals include references to NLS in some form; typically these are citations of collections or acknowledgements to staff who have assisted with research. Increasingly, it should be possible to identify such references electronically through resources such as Google Books and Google Scholar. This would generate hard data on the extent to which NLS has contributed to publications, through the research and productivity of our users. Ultimately, a key outcome that national libraries want to achieve may be phrased as 'generating knowledge and understanding'. Whilst this bibliometric measure would not address the quality of publications produced using NLS resources, it may be one of the best possible proxy measures in the near future.

(Hunter, 2009, 7)

It has been noted that an "organisation's work should always be measurable, even if it must use proxies to do so." (Kasturi Rangan, 2004). It is not therefore surprising that there is rising interest in the scope for bibliometric evaluation:

As bibliometric indicators are objective, reliable, and cost-effective measures of peer-reviewed research outputs, they are expected to play an increasingly important role in research assessment/management.

(Campbell et al., 2010, 66)

A topical debate about the merits of this approach has centred around the Research Excellence Framework (REF). Clearly there are concerns that over- 
reliance on bibliometrics is inappropriate: in responses to the initial REF consultation, it "was widely commented that bibliometrics do not provide a direct measure of quality, but provide a proxy indicator of quality" (HEFCE 2008, 9). In describing the REF 2014, HEFCE states that a

pilot exercise showed that [bibliometric] citation information is not sufficiently robust to be used formulaically or as a primary indicator of quality; but there is considerable scope for it to inform and enhance the process of expert review.

(HEFCE, 2011)

This paper describes our preliminary attempt to apply simple bibliometric tools such as web mention analysis in order to quantify the research outputs created by our users; these research products representing a surrogate or proxy for 'generating knowledge and understanding'.

\section{Methodology - testing a bibliometric approach to measuring the value of NLS}

In essence, the methodology described in this paper is an attempt to quantify the number of publications produced which cite NLS. This is carried out through the interrogation of a number of research resources and databases which bring together varied online content. In the absence of an unambiguous term for these diverse resources, for the purposes of this paper we call these resources and databases 'Aggregated Research Gateways' (ARGs). Five ARGs were studied: Google Scholar, JSTOR, Web of Knowledge, Oxford Journals Online and Science Full Text Select 2000-2010. These resources were selected to provide a range of material in terms of subject matter and to encompass a range of formats such as journals and books. As we shall see, our focus became directed very much to the first two of these.

Unless otherwise indicated, all data is based on searches carried out on 2 November 2010. Searches were run in each resource to establish the number of exact mentions of 'National Library of Scotland'. These searches were done both in total (i.e. without any time limits specified) and also by year, to generate both aggregate and trend information. We also sampled these hits to explore some of them in greater detail, in order to gain insight into the type of material that was being picked up from these searches and to confirm that they were indeed research products citing some genuine interaction with the Library.

In addition to looking for references to NLS, we also searched for citations of four other national libraries to provide benchmarks and effectively to triangulate the search findings for NLS. These four libraries were the British Library (BL), National Library of Wales (NLW), National Library of Australia (NLA) and the National Library of the Netherlands (KB). 


\section{Findings}

\subsection{NLS}

Our headline figures (with no limits of time or other parameters) show the following total results for each ARG for NLS:

\begin{tabular}{|l|r|l|l|l|l|}
\hline & & $\begin{array}{l}\text { Google } \\
\text { Scholar (all) }\end{array}$ & $\begin{array}{l}\text { Web of } \\
\text { Knowledge }\end{array}$ & $\begin{array}{l}\text { Oxford } \\
\text { Journals } \\
\text { Online }\end{array}$ & $\begin{array}{l}\text { Science Full } \\
\text { Text Select } \\
2000-2010\end{array}$ \\
\hline NLS & 2,372 & 9,820 & 18 & 1,122 & 4 \\
\hline
\end{tabular}

Table 1: NLS hits by ARG (note: these totals cannot be added up meaningfully, because a single article may appear in two or more ARGs.).

The first notable observation is that the scale of content held by Google Scholar far surpasses any other resource; this also applies when we look at the results for other national libraries below. The figures appear to indicate that NLS has contributed to a minimum of some 10,000 publications.

Because of the relatively low number of hits obtained from the Web of Knowledge, Oxford Journals Online and Science Full Text Select 2000-2010, our subsequent analysis was confined to JSTOR and Google Scholar as the holders of the greatest content. However, it may be useful to return to these resources on order to understand more about how their results are derived - particularly for Oxford Journals Online which reports a significant number of NLS citations. Table 2 shows the annual hits for NLS for recent years from Google Scholar and for JSTOR:

\begin{tabular}{|l|l|l|l|l|l|}
\hline Year & 2005 & 2006 & 2007 & 2008 & 2009 \\
\hline Google Scholar & 398 & 407 & 450 & 395 & 360 \\
JSTOR & 32 & 37 & 19 & 9 & 8 \\
\hline
\end{tabular}

\section{Table 2: NLS hits by year (Google Scholar and JSTOR).}

Google Scholar again reports most 'hits'; we see that in recent years, some 400 publications a year appear to cite NLS. In the past two years, the reported hits decline significantly, particularly for JSTOR. This can probably be attributed to the licensing policy of JSTOR which has a 'moving wall' to exclude much recent journal content, in order to protect publishers' revenue. It is not so obvious why a time-lag necessarily applies to Google Scholar, but there may also be a delay in digitising the most recent material to the resource. It has been noted that there may be a considerable delay (of years) "as citations often take several years to start to appear in the scholarly literature as research is completed, written up and published" (Meyer et al., 2009, 19).

\subsection{Benchmark libraries}

In this section we look at similar data - but rather than for NLS alone, the results are shown for citations of the members of our club of four benchmark libraries British Library (BL), National Library of Wales (NLW), National Library of Australia (NLA) and the National Library of the Netherlands (KB), in addition to NLS. Table 3 shows these results. 


\begin{tabular}{|l|r|l|l|l|l|r|}
\hline & & \multicolumn{1}{l|}{$\begin{array}{l}\text { Google } \\
\text { Scholar } \\
\text { (all) }\end{array}$} & $\begin{array}{l}\text { Web of } \\
\text { Knowledge }\end{array}$ & $\begin{array}{l}\text { Oxford } \\
\text { Journals } \\
\text { Online }\end{array}$ & $\begin{array}{l}\text { Science } \\
\text { Full Text } \\
\text { Select }\end{array}$ & \\
& JSTOR & 2000-2010 & Totals \\
\hline NLS & 2,372 & 9,820 & 18 & 1,122 & 4 & 13,336 \\
BL & 17,626 & $1,770,000$ & 519 & 6,310 & 142 & $1,794,597$ \\
NLW & 1,206 & 5,360 & 33 & 659 & 1 & 7,259 \\
NLA & 897 & 33,300 & 35 & 83 & 16 & 34,331 \\
KB & 646 & 10,700 & 23 & 75 & 0 & 11,444 \\
Totals & $\mathbf{2 2 , 7 4 7}$ & $\mathbf{1 , 8 2 9 , 1 8 0}$ & $\mathbf{6 2 8}$ & $\mathbf{8 , 2 4 9}$ & $\mathbf{1 6 3}$ & $\mathbf{1 , 8 6 0 , 9 6 7}$ \\
\hline
\end{tabular}

Table 3: Hits identified through different 'Aggregated Research Gateways'.

Again, it is striking that by far the most hits are reported through Google Scholar. Indeed, for the group of benchmark libraries, this result is far more pronounced than for NLS alone. Whereas NLS accounts for $10 \%$ of all JSTOR hits for the five libraries, it accounts for only $0.5 \%$ of all Google Scholar hits. The figures clearly confirm that the scale of content held by Google Scholar surpasses any other resource; but they also suggest that the pattern of hits picked up by each ARG may vary.

The second clear feature is the predominance of the British Library. Of course, as one of the world's largest and most important research libraries, we would expect the BL to appear prominently in the results. However, while the BL accounts for $97 \%$ of all Google Scholar hits, it accounts for only $77 \%$ of JSTOR hits. A possible reason for this is the role of many national libraries (including BL) in maintaining a national bibliography; meaning that a statement such as "a catalogue record for this book may be obtained from the British Library" appears on the publishers' details page of many British monographs. This might be picked up by Google Scholar, but not JSTOR and would therefore artificially inflate the Google Scholar hits. This suspicion appears to be supported by observing on closer inspection that Google Scholar accounts for over 93\% of the hits for BL, KB and NLA - all national libraries that maintain cited national catalogues. For NLS and NLW, on the other hand (which are not routinely cited on publications in this way) the figure is less than $74 \%$ (Table 4). This suggests that the figures may indeed be distorted by the reference to national libraries which maintain a routinely-cited national bibliography.

We did a small number of experiments to gauge the effect of 'false positive' counting of 'national bibliographic' citations for the British Library, National Library of Australia and Koninklijke Bibliotheek. Surprisingly, excluding the phrases 'catalogue record' AND 'cataloguing in publication' from the query only reduced Google Scholar citation counts for 2009 by between 1 and 4 percent for the BL and KB, but by over $50 \%$ for the National Library of Australia. No explanation of this difference is immediately obvious to us, but it is noticeable that the NLA list of hits is dominated by publications of the Library's staff in the journal 'National Library of Australia Staff Papers'. Also, we note that the British Library in its current form and name has only been in existence since 1973; this explanation may not hold water for earlier publications and requires more detailed investigation. 


\begin{tabular}{|l|l|l|l|l|l|l|}
\hline $\begin{array}{l}\text { ARP: } \\
\text { \% of total } \\
\text { hits }\end{array}$ & JSTOR & $\begin{array}{l}\text { Google } \\
\text { Scholar } \\
\text { (all) }\end{array}$ & $\begin{array}{l}\text { Web of } \\
\text { Knowledge }\end{array}$ & $\begin{array}{l}\text { Oxford } \\
\text { Journals } \\
\text { Online }\end{array}$ & $\begin{array}{l}\text { Science Full } \\
\text { Text Select } \\
2000-2010\end{array}$ & Totals \\
\hline NLS & 17.8 & 73.6 & 0.1 & 8.4 & 0.0 & $\mathbf{1 0 0 . 0}$ \\
BL & 1.0 & 98.6 & 0.0 & 0.4 & 0.0 & $\mathbf{1 0 0 . 0}$ \\
NLW & 16.6 & 73.8 & 0.5 & 9.1 & 0.0 & $\mathbf{1 0 0 . 0}$ \\
NLA & 2.6 & 97.0 & 0.1 & 0.2 & 0.0 & $\mathbf{1 0 0 . 0}$ \\
KB & 5.6 & 93.5 & 0.2 & 0.7 & 0.0 & $\mathbf{1 0 0 . 0}$ \\
\hline
\end{tabular}

Table 4: Percentage of hits by ARG.

If this 'national bibliography issue' at least partially explains the high number of hits for BL, NLA and KB, it suggests that we cannot compare NLS and NLW performance with these libraries using Google Scholar, unless we can develop an effective way to filter out these 'technical' references. Looking at the reported hits from JSTOR plotted by recent year for the six libraries (Table 5), the time-lag noted for NLS above is broadly confirmed:

\begin{tabular}{|l|l|l|l|l|l|}
\hline Year & 2005 & 2006 & 2007 & 2008 & 2009 \\
\hline Hits & 1,048 & 1,081 & 534 & 423 & 234 \\
\hline
\end{tabular}

\section{Table 5: JSTOR hits by year (all five benchmark libraries).}

As can be seen, the reported hits decline considerably over recent years; this appears to confirm that JSTOR is not suitable for monitoring the most recent publications and the time lag of useful data is possibly at least four years from publication date to appearance in JSTOR. Certainly this decline does not correlate to the general trend of research publication outputs, which UK government reports have indicated had increased by over 10\% in 2008 (Department for Business, Innovation and Skills, 2009).

While there appear to be problems in comparing Google Scholar data for NLS with national libraries that maintain national bibliographies, we can compare the NLS findings with the National Library of Wales with some confidence. Both libraries show a similar pattern of increased number of hits to 2007, with a subsequent decline (Figure 1). 


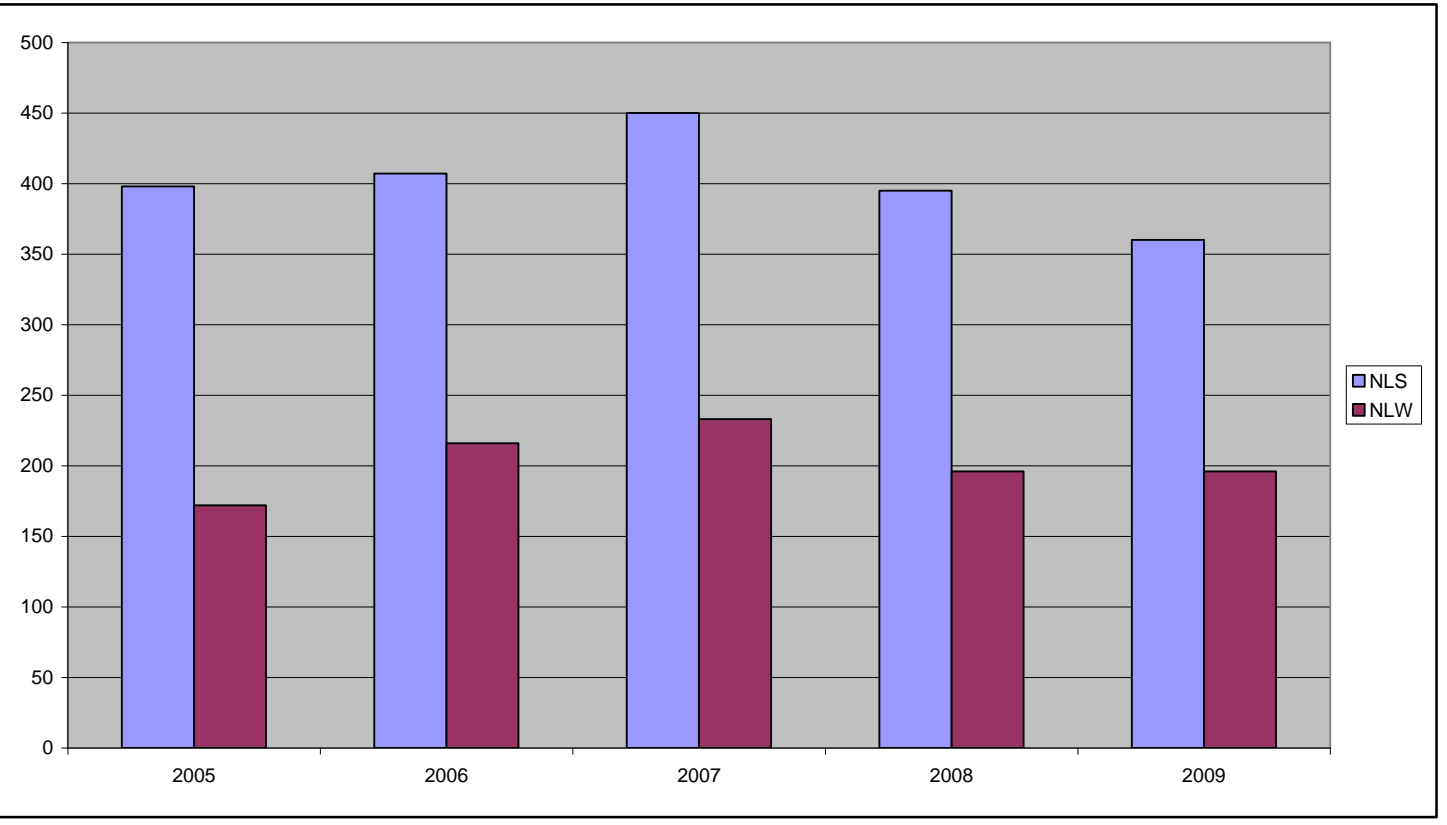

\section{Figure 1: NLS and NLW hits from Google Scholar.}

This pattern is broadly replicated by the figures for the British Library (Figure 2), but less so for the national libraries of Australia and the Netherlands where no tail-off is apparent (Figure 3). The reason for these different patterns between the libraries is not known.

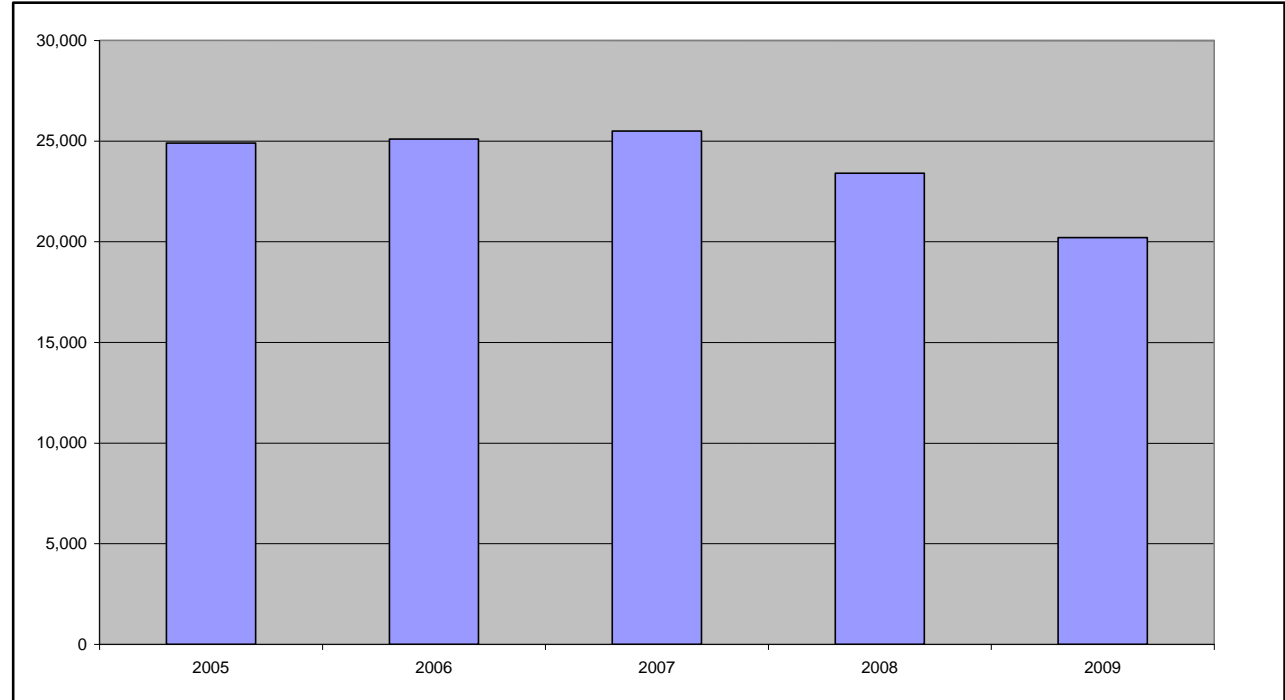

Figure 2: British Library hits from Google Scholar. 


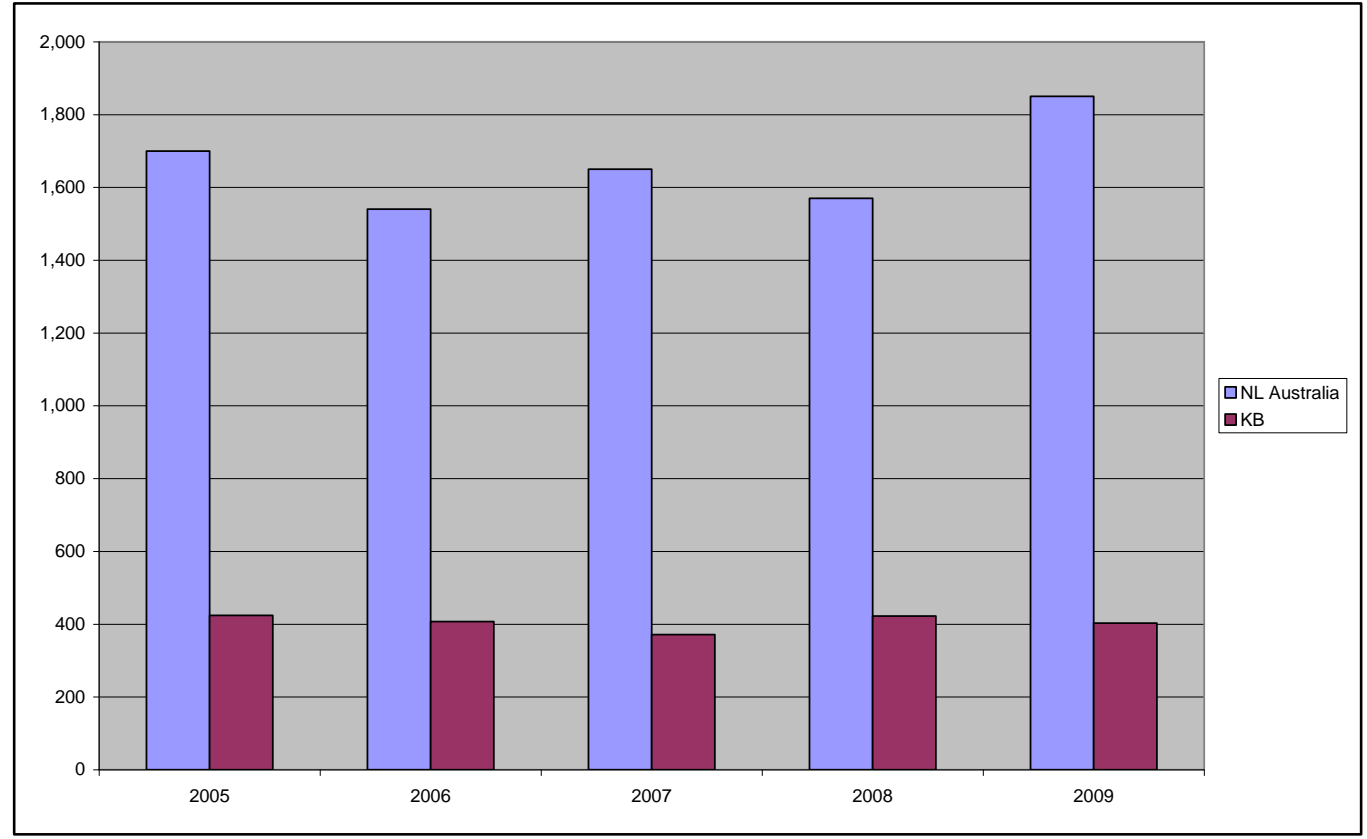

Figure 3: National libraries of Australia, Netherlands hits from Google Scholar.

\subsection{A closer look at the reported citations}

Until now, we have confined ourselves simply to raw counts of hits. What kind of reference or citation do these hits represent, and how can we be sure that each hit really represents a genuine citation? We can conceptualise publications as falling into one of the four categories indicated in Figure 4. We would hope, if the methodology was sound, that the great majority of hits would fall into box B where a reported hit did indeed represent a real citation. However, it is possible that some hits pick up a purely contingent or accidental reference to NLS such as "Edinburgh's Central Library is opposite the National Library of Scotland on George IV Bridge" which would fall into box A. Equally, it is possible that a publication to which NLS made a genuine contribution is not picked up in a hit (box D). (Box C represents no reference to NLS, which properly, should result in no hit.) 


\begin{tabular}{|c|c|c|}
\hline 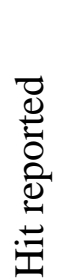 & $\begin{array}{l}\text { A } \\
\text { 'false positive' - citation } \\
\text { reported inappropriately } \\
\times\end{array}$ & $\begin{array}{c}\text { B } \\
\text { Genuine citations } \\
\text { picked up } \\
\checkmark\end{array}$ \\
\hline $\begin{array}{l}\stackrel{\Xi}{\Xi} \\
\stackrel{0}{Z}\end{array}$ & $\begin{array}{c}\text { C } \\
\text { No genuine citations, } \\
\text { no hits } \\
\checkmark\end{array}$ & $\begin{array}{c}\text { D } \\
\text { Missing results } \\
\text { (number unknown) } \\
\times\end{array}$ \\
\hline & $\begin{array}{l}\text { NLS collections not used } \\
\text { in publication }\end{array}$ & $\begin{array}{l}\text { NLS collections used in } \\
\text { publication }\end{array}$ \\
\hline
\end{tabular}

\section{Figure 4: Classification of research publications.}

In order to explore the nature of these citations, a random sample of 37 hits was examined, representing 10\% of all Google Scholar hits for NLS 2009 (Appendix 1). It appears that almost all of these citations were 'genuine' (Figure 4, box B) with no clear 'false positives' (Figure 4, box A) identified. Although this is only a small sample, it suggests that the headline figures noted above for research publications produced using NLS can indeed be accepted with a fair degree of confidence.

Most of the publications that cited NLS were books (43\%) or journal articles. Mentions of NLS were predominantly in an opening 'Acknowledgements' section $(30 \%)$ or in 'References', citing collection holdings (22\%). It is noticeable that many of the citations refer to 'special collections' of manuscripts or rare books [41\%].

However, these figures raise a number of other questions. NLS has internationally-important manuscript collections, but the citation of manuscript material especially reported here is out of proportion to the use of manuscripts by NLS users (at least, by on-site readers). This may suggest that authors using manuscript materials may be more likely to cite NLS than those using other materials. This has an intuitive logic, in that manuscripts tend to be unique by their nature; an author citing a manuscript might therefore be more inclined to state where this document was accessed (in this case, NLS) than an author consulting a book or other resource which could be accessed at a number of locations. On the other hand, it must be conceded that a researcher citing a manuscript at NLS may do so without ever having used the Library (the knowledge that the manuscript is held by NLS sufficing for their needs).

The key implication of this finding is that this bibliometric method is likely to under-report, rather than over-report, the number of publications produced using NLS. The total number of publications produced, using books, journals, maps film 
and other collections less visible in the pattern of hits reported here, is likely to be considerably larger. But how much larger? We cannot say if it might be $10 \%$, $50 \%$ or $400 \%$ larger.

\section{Methodological issues and concerns}

It is fully accepted that the methodology adopted in this paper may be criticised on a number of grounds. There will always be concerns at using proxies (in this case, references in research outputs) to represent a high-level outcome (in this case, the creation of knowledge). Much valuable research carried out using NLS will result in no formal publication being produced. Research carried out which does lead to a publication may not cite NLS. Those citations in research publications which are picked up through this methodology may be superficial or 'technical' - without the library having had an important role in the production of the research. The methodology doesn't take account of other national library roles - for example preserving the national published record (irrespective of whether or not it is being used), or promoting awareness of national collections through education, talks and exhibitions. The role of national libraries in fostering collaboration and best practice is effectively ignored.

Another objection with this methodology may be its Anglocentric approach. We have largely focussed on major libraries of the English-speaking world; no attempt has been made to extend the methodology to the great libraries of France, Egypt, Russia, China and elsewhere in the world.

As the section above indicates, some of the hits produced by the methodology do not represent a real contribution by the libraries to a research output, and may therefore be discounted. Conversely however, we know from personal experience that much research which has used NLS collections or services is published without citing NLS; this must cause these figures to under-state the contribution of national libraries. This may be increasingly the case in the digital environment, where digitised surrogates are used (and perhaps cited) by authors, rather than the original paper text itself.

There also appear to be technical objections that may be raised by some of the findings above - for example, the possible inflation of Google Scholar hits attributed to the essentially administrative reference to national bibliography as discussed above, may be a serious weakness.

Finally, and most obviously, there is the simple point that, just because something is published, it does not necessarily mean that it is any good, or that it makes a significant contribution to knowledge and wisdom. The methodology makes no distinction between high-quality and low quality publications (and there is no objective measure of quality).

All these issues might usefully be explored by others who have a deeper understanding of the way that such ARGs collect and report data. 


\section{Conclusions}

Despite these potential objections and weaknesses, we maintain that the approach has a fundamental validity. We see the technique we outline here as a practical attempt to use webometric techniques along the lines described in, for example, Meyer (2011) and Meyer et al. (2009) to examine 'impact' quantitatively.

We should expect national libraries to stimulate published research. National Library collections represent assets for their nation which have the potential to foster all kinds of creativity, innovation and insight. The proper exploitation of these assets (and the knowledge of their curators) is central to the mission of national libraries. We should expect that these collections are used productively to an increasing extent, as all kinds of knowledge (held in books, manuscripts, film or any other format) become easier to find, use and join together as improvements in digital services and capabilities continue. This is an outcome which society and our funders can rightly expect to see as a result of their investment in and support of national libraries.

To summarise our specific conclusions:

- At least some 10,000 publications have been produced in total using NLS collections or services

- At least 400 more such publications are generated each year;

- Our sampling of these publications confirms that generally speaking, these do represent genuine references/citations;

- The true figure is likely to be greater, perhaps very considerably greater, but it is not yet possible to quantify the scale of under-reporting;

- JSTOR is a useful resource for exploring older publications, but not for measuring current outputs;

- Google Scholar appears to be the most comprehensive and best resource for current material, although it is difficult to use to compare one library with another, and again current research may take time to appear;

- Other ARGs are too small or specialised in content to be used for these purposes.

It is only quite recently that international standards for national libraries have been developed (see Poll and Boekhorst, 2007, 31-8). At present however, standards [do] not include performance indicators for evaluating the outcomes or impact of library services either on individuals, on the communities that libraries serve, or on society at this time. Since this is an evolving area of performance measurement for libraries, such performance indicators can be added at a later date.

(International Organization for Standardization, 2009)

As such, we believe that there is benefit in pursuing this methodology, which could contribute some tangible data to the evaluation of impacts and outcomes. These are difficult to capture through traditional management information such as Key Performance Indicators, which NLS has used as its principal performance 
management tool since 2005. This is not to suggest for a moment that it is the only way to evaluate the impact of national libraries. Other methods have included the contingent valuation methodology, notably through the British Library's Demonstrating Value work of 2004. Of course, qualitative as well as quantitative dimensions are important and a balanced evaluation approach will no doubt encompass a range of techniques. However, we suggest there is merit in attempting to develop this bibliometric element further, and would hope that others with particular expertise in analysis of search and digital publishing might further develop and explore this approach.

\section{References}

British Library (2004) Measuring our value: results of an independent economic impact study commissioned by the British Library to measure the Library's direct and indirect value to the UK economy. London: British Library.

Campbell, D. et al. (2010) Bibliometrics as a performance measurement tool for research evaluation: the case of research funded by the National Cancer Institute of Canada, American Journal of Evaluation, 31(1), 66-83.

Department for Business, Innovation and Skills (2009) International comparative performance of the UK Research Base. URL:

http://www.dius.gov.uk/assets/biscore/corporate/migratedd/publications/i/icpruk0 9v14.pdf [accessed 17.5.2011].

HEFCE (2008) Analysis of responses to HEFCE 2007/34, the Research Excellence Framework consultation. URL:

http://www.hefce.ac.uk/pubs/consult/outcomes/ref.doc [accessed 18.5.2011].

HEFCE (2011) REF 2014: bibliometrics pilot exercise. URL:

http://www.hefce.ac.uk/research/ref/Biblio/ [accessed 04.01.2012].

Hunter, D. (2009) The development of strategic performance information at the National Library of Scotland, Performance Measurement and Metrics 10(2), 14250 [online]. URL:

http://www.isast.org/proceedingsQQML2009/PAPERS_PDF/Hunter-

Development_of_strategic_performance_indicators_at_Scotland_PAPERQQML2009.pdf [accessed 17.5.2011].

International Organization for Standardization (2009) Information and documentation: performance indicators for national libraries. [ISO/TR 28118:2009].

Kasturi Rangan, V. (2004) Lofty missions, down-to-earth plans, Harvard Business Review, 82(3), 112-29.

Meyer, E.T. (2011) Splashes and ripples: synthesizing the evidence on the impact of digital resources. London: JISC. URL: http://ssrn.com/abstract=1846535 [accessed 2011]. 
Meyer, E.T., Eccles, K., Thelwall, M., Madsen, C. (2009) Final Report, 20 July 2009. Usage and impact study of JISC-funded Phase 1 digitisation projects \& the toolkit for the impact of digitised scholarly resources (TIDSR). Oxford: Oxford Internet Institute.

Poll, R. and Boekhorst, P. te (2007) Measuring quality: performance measurement in libraries. Munchen: K.G. Saur. 


\section{Appendix 1: Google Scholar search results for "National Library of Scotland 2009"}

\section{Item details}

Barfoot, M. (2009) David Skae: resident asylum physician, scientific general practitioner of insanity, Medical History, 53(4), 469-88.

Beach, J. (2009) De l'art de la reconnaissance au livre jaune : le renseignement militaire britannique, 19021915, Guerres mondiales et conflits contemporains, 2008/4, no. 232.

Boswell, J. (1936) Journal of a tour to the Hebrides with Samuel Johnson. New York: Heinemann. URL: http://library.du.ac.in/xmlui/bitstream/handle/1/7822/Ch $.03 \% 20$ Boswell\%20Journal\%200f\%20Tour\%20To\%20 The\%20hebrides\%20(401457)\%20page.pdf?sequence $=1$ [accessed 2.11.2010].

Bruckner, M. T. (2009) Chretien continued: a study of the Conte du Graal and its verse continuations. Oxford: Oxford University Press.

Carruthers, A. (2009) The social rise of the Orkney Chair, Journal of Design History, 22(1) 27-45.

Conway, S. (2009) Christians, Catholics, Protestants: the religious links of Britain and Ireland with continental Europe, c.1689-1800, English Historical Review, 124(509), 833-62.

Desmond, A. and Moore, J. (2009) Darwin's sacred cause: race, slavery and the quest for human origins. London: Allen Lane.

Farrell, S. (2009) Archaeological watching brief of a development at Plot 2, Drover's Stance, Ardross, by Alness, Highland. URL:

http://her.highland.gov.uk/hbsmrgatewayhighland/Data Files/LibraryLinkFiles/152070.pdf [accessed 2.11.2010]

Fauset, E. (2011) The politics of writing: Julia Kavanagh, 1824-77. Oxford: Oxford University Press.
Nature/context of occurrence of "National Library of Scotland"

Acknowledges Library/collections MSS. in particular.

Cites NLS MSS.

Unable to find mention of NLS.

Cites NLS MSS.

Cites NLS

collections.

Cites NLS MSS.

Acknowledges NLS staff/collections.

\section{Cites NLS}

collections.

[Unable to identify book not held in NLS.] 
Fimi, D. (2009) Tolkien, race and cultural history: from fairies to hobbits. Basingstoke: Palgrave Macmillan.

Fulton, H. (ed.) (2009) A companion to Arthurian literature. Chichester: Wiley-Blackwell.

Grigg, J. A. (2009) The lives of David Brainerd. New York: Oxford University Press.

Hennessy, M. V. (2009) Tributes to Kathleen L. Scott : English medieval manuscripts: readers, makers and illuminators. London: Harvey Miller

Identification des editions. Selection par pays de catalogues de bibliothèques en ligne contenant des notices de livres anciens (n.d.) URL: http://theleme.enc.sorbonne.fr/document262.html [accessed 2.11.2010].

Kuhns, J. (2009) The pre-19th-century manuscript tradition and textual transmission of the Early Modern Irish tale Oidheadh Con Culainn: a preliminary study. $\mathrm{PhD}$ thesis, University of Glasgow.

Lowe, P. (2009) Contending with nationalism and communism: British policy towards Southeast Asia, 1945-65. Basingstoke: Palgrave Macmillan.

McCleery, A. (2009) The 1969 edition of Ulysses: the making of a Penguin classic, James Joyce Quarterly 46(1), 55.

McGrath, M. (2009) Interlending and document supply: a review of the recent literature. 68, Interlending and Document Supply 37(3), 156-63.

Martin, J. (2009) Responses to the frame narrative of John Gower's Confessio amantis in fifteenth- and sixteenth-century Scottish literature, Review of English Studies, 60(246), 561-77.

Novokhatko, A. (2009) The invectives of Sallust and Cicero. Berlin: Walter de Gruyter.

Opstad, G. (2009) Debussy's : : the lives of Georgette Leblanc, Mary Garden and Maggie Teyte. Woodbridge: Boydell.

Osborne, B. D. (2009) The people's army: the Home Guard in Scotland. Edinburgh: Birlinn.
Acknowledges

permission to reproduce from NLS collections.

Cites NLS MSS.

Acknowledges NLS staff/collections.

Cites NLS

collections.

Cites NLS

publication.

Acknowledges NLS MSS.

Acknowledges NLS MSS.

Acknowledges NLS staff/collections.

Reference to legal deposit.

Cites NLS MSS.

[Unable to check.]

Cites NLS MSS.

Acknowledges staff $\&$ permission to reproduce from NLS collections. 
Philpott, W. (2009) Bloody victory: the sacrifice on the Somme. London: Little, Brown.

Ritchie, A. (2009) Major accessions to repositories in 2008 relating to politics, Contemporary British History, 4(23), 573 .

Rodriguez-Gil, M.A. and Yanez-Bouza, N. (2009) The ECEG-database: a bio-bibliographical approach to the study of eighteenth-century English grammars. In: Tieken-Boon van Ostade, I. and Wurff, W. van der (eds.) Current issues in late modern English. Bern: Peter Lang [Linguistic Insights; vol. 77. International Conference on Late Modern English ( $3^{\text {rd }}: 2007$ : University of Leiden)].

Rudy, J. (2009) Electric meters: Victorian physiological poetics. Athens, Ohio: Ohio University Press.

Russell, M. (2009) Soviet montage cinema as propaganda and political rhetoric. $\mathrm{PhD}$ thesis, University of Edinburgh. URL: http://www.era.lib.ed.ac.uk/handle/1842/4084 [accessed 2.11.2010]

Scholarly communications report (2009)

Scully, R and Quartly, M. (2009) Drawing the line: using cartoons as historical evidence. Clayton, Vic.: Monash University Press.

Selwood, S. (2009) Museums, galleries and the visual arts. In: Jeffcut, P. (ed.) Creativity, innovation and the cultural economy. Abingdon: Routledge.

Sargent, G. (2010) The Scottish literary renaissance reborn: a re-evaluation of the cultural directives of King James VI, as defined in his Essayes of a Prentise in the Divine Art of Poesie (1584). MPhil thesis, University of Glasgow. URL: http://theses.gla.ac.uk/1657/ [accessed: 2.11.2010]
Acknowledges staff $\&$ permission to reproduce from NLS MSS.

\section{Cites NLS}

collections.

Cites NLS

collections.

Acknowledges NLS staff/collections.

Acknowledges NLS staff/collections.

[Article on legal deposit - no other bibliographic details cited apart from link to www.atyponlink.com.]

Cites NLS collections.

Passing mention of NLS.

Cites NLS

collections. 
Serjeantson, R. and Woolford, T. (2009) The Scribal

Cites NLS MSS.

Publication of a Printed Book: Francis Bacon's Certaine considerations touching ... the Church of England (1604), The Library: the Transactions of the Bibliographical Society, 10(2), 119-56.

Stokes, M. (2009) Bilive and blive: distribution and metrical function, Journal of English and Germanic philology, 108(2), 190.

Wellburn, P. (2009) Review of A companion to Latin American literature and culture, Reference reviews, 23(5), 32 .

Whyte, D. (1972) A dictionary of Scottish emigrants to the USA. Baltimore: Maryland.

Yaitsky, L. (2009) "God help Tristrem the knight!|He faught for Ingland": a narrative and manuscript study of English identity in Sir Tristrem. MA Thesis, Florida State University. URL: http://etd.lib.fsu.edu/theses/available/etd-07082009151933/ [accessed 2.11.2010]

Yhu, H. (2009) Darwin's Origin of Species was nearly rejected.

Cites Auchinleck MS.

Passing mention of NLS catalogue inclusion in COPAC.

"False positive". Book published in 1972, digitised by Google Books in 2009.

Cites NLS MSS.

[Unidentifiable citation.]

\section{Open access and copyright}

Library and Information Research is an open access journal. A freely available copy of this paper may be downloaded from the journal's website: http://www.cilipjournals.org.uk/lir.

Copyright and associated moral rights in works published in Library and Information Research are retained by the author(s) but this paper may be used freely, with proper attribution, in educational and other non-commercial settings. 